\title{
Grandes sistemas fluviais tropicais: uma visão geral
}

\author{
Edgardo M. Latrubesse ${ }^{1}$; José Cândido Stevaux² e Rajiv Sinha ${ }^{3}$ \\ 1-Universidade Federal de Goiás-IESA-LABOGEF, Campus II, 74001-970 Goiânia-GO, Brasil. E-mail: \\ latrubes@terra.com.br \\ 2-Universidade Guarulhos, Lab. Geociências, Pr. Tereza Cristina, 1, 07023-070 Guarulhos, SP, Brasil \\ 3-Technologic Institute of India, Kanpur, India
}

\begin{abstract}
Resumo
Muitos dos grandes rios e dos leques aluviais existentes estão situados em áreas tropicais e constituem os maiores sistemas de estoque e transferência de sedimentos e nutrientes para o oceano. O presente trabalho visa a apresentação e análise geral dos grandes sistemas fluviais e leques aluviais (área da bacia entre 104 e 6 x $106 \mathrm{~km}^{2}$ ) de regiões tropicais com precipitação acima de $700 \mathrm{~mm}$ anuais. Os grandes sistemas fluviais tropicais foram aqui classificados de acordo com o arcabouço geológico-geomorfológio de suas bacias em: a) Cinturões orogenênicos de montanha, b) Platô/plataforma basáltico-sedimentar, c) Áreas cratônicas, d) Planícies em áreas de bacias sedimentares, e e) Áreas mistas. De modo geral, os rios analisados apresentam um pico de descarga bastante definido e variável durante a estação chuvosa e um período de baixa vazão na estação seca. Os dados dos rios sul-americanos e asiáticos de áreas continentais e orogênicas agruparam-se quando lançados num diagrama do suprimento de sedimentos versus descarga média anual, e apresentaram valores mais elevados que aqueles asiáticos insulares. Já rios de áreas de plataforma ou cratônicas, tanto em área de savana como nos trópicos úmidos, caracterizaram-se por terem baixo transporte de sedimento. Especialmente nas grandes bacias, os rios apresentam toda a gama de formas de canal, inviabilizando a classificação tradicional de canal meandrante, reto e entrelaçado, sendo nesse caso mais sugestiva a aplicação da terminologia de sistema uni ou multi-canal ou de complexo anastomosado.É também discutido, brevemente, o atual estado do conhecimento dos sistemas fluviais tropicais e seu potencial na aplicação na interpretação de antigas seqüências e na modelagem de fácies sedimentar. Os principais impactos ambientais a que os grandes sistemas fluviais tropicais estão submetidos incluem as mudanças no uso agrosilpastoril das terras, mineração, barragens e transposição de bacias. $\mathrm{O}$ risco e o dano de grandes enchentes são também discutidos.
\end{abstract}

Palavras-chave: grandes rios, sistemas fluviais tropicais, classificação

\begin{abstract}
This paper presents an overview of large tropical river systems (river basin area from 104 and $6 \times 106 \mathrm{~km}^{2}$ ) around the world and identifies major knowledge gaps. We focus particularly on the rivers draining the wet and wet-dry tropics with annual rainfall totals more than $700 \mathrm{~mm} /$ year.The tropical rivers across the globe drain a variety of geologicgeomorphologic settings: (a) orogenic mountains belts, (b) Sedimentary and basaltic plateau/platforms, (c) cratonic areas, (d) lowland plains in sedimentary basins and (e) mixed terrain. All of them show clear high but variable peak discharges during the rainy season and a period of low flow when rainfall decreases. Some tropical rivers show two flood peaks, a principal and a secondary one, during the year. We computed the intensity of floods and discharge variability in tropical rivers. The relationship between sediment yield and average water discharge for orogenic continental rivers of South America and Asia was also plotted. Insular Asian rivers show lower values of sediment yield related to mean annual discharge than continental orogenic rivers of Asia and South America. Rivers draining platforms or cratonic areas in both, savanna and wet tropical climates, are characterized by low sediment yields. Tropical rivers exhibit a large variety of channel form. In most cases, and particularly in large basins, rivers exhibit a transition from one form to another so that traditional definitions of straight, meandering and braided may be difficult to apply. In general it is more useful to apply the terminology of single and multi-channel systems or complex anabranching systems at least for selected regional segments.

Present day knowledge of tropical systems and its potential application to improve interpretation of older alluvial sequences and facies models is briefly discussed. Human impacts and management, including land use changes, mining, dams, interbasin water transference, as well flood hazards are considered as the main impacts in tropical basins.
\end{abstract}

Key words: large rivers, tropical fluvial systemns, cassidfication 


\section{Introdução}

Durante as últimas décadas ocorreu um grande avanço na geomorfologia fluvial, principalmente no tocante aos grandes sistemas fluviais de ambos hemisférios que se estendem por diferentes zonas climáticas. Mais precisamente, esses estudos enfocaram os processos morfogenéticos (Coleman, 1969; Sabat, 1975 Tricart, 1977; Baker, 1978; Pickup, 1984; Pickup \& Warner, 1984; Tricart et al., 1984; Iriondo \& Suguio, 1981, Iriondo, 1993; Drago, 1990; Thorne et al., 1993; Mertes, 1994; Mertes et al., 1996; Sinha, 1996; Stevaux, 1994; Dunne et al, 1998, Goswamy, 1998; Dietrich et al., 1999; Latrubesse \& Franzinelli, 2002; Orfeo \& Stevaux, 2002; Latrubesse \& Stevaux, 2002: Ramonell et al., 2002 e outros); os processos sedimentológicos e hidro-sedimentológicos (Smith, 1986; Bristow, 1987; Nordin \& Perez Hernandes, 1989; Stevaux \& Santos, 1998; Santos \& Stevaux, 2000; Vital \& Stattegger, 2000; Warne et al., 2002); a hidrologia de inundação (Sinha and Jain, 1998; Dhar and Nandargi, 2000; Kale, 1998; Latrubesse et al., 2002); e a relação entre o tectonismo e os processos fluviais (Iriondo and Suguio, 1987; Goswamy, 1988; Dumont, 1993; Dumont \& Fournier, 1994; Franzinelli and Igreja, 2002; Latrubesse and Rancy, 2000). Mesmo assim, tendo em vista a grande extensão das regiões tropicais e a magnitude de seus rios, pode-se dizer que o conhecimento dos rios tropicais ainda é bastante limitado.

O objetivo deste trabalho é apresentar uma visão geral dos sistemas tropicais do mundo salientando suas diferenças e similaridades quanto ao clima e arcabouço geológico de suas bacias, ao regime hidrológico que os controlam, aos processos morfogenéticos e hidrológicos a que estão submetidos, aos impactos introduzidos pelo homem e os problemas deles advindos, apontando os principais hiatos em seu conhecimento. Serão particularmente tratados os rios que drenam os trópicos úmidos e úmidos-secos, cuja precipitação está acima de $700 \mathrm{mmm} /$ ano e o tamanho de suas bacias hidrográficas está entre 103 a $106 \mathrm{~km} 2$. Os dados hidrográficos utilizados foram obtidos na base de dados disponíveis na "Internet", como por exemplo www.gdrc.sr.unh.edu, e de agências nacionais como a Agência Nacional da Água, Brasil (ANA) e Central Water Comission, India (CWC).

\section{Trópico úmido e úmido-seco}

As regiões tropicais definem-se geograficamente entre os trópicos de Câncer $\left(2327^{\prime} \mathrm{N}\right)$ e o de Capricórnio (2327'S). A grande quantidade de energia solar nessas áreas gera um clima praticamente sem invernos. A incidência solar se faz em ângulos altos com pequena variação na extensão dos dias entre 12-13 horas. A temperatura média é aproximadamente constante, apresentando a mesma variação do dia para a noite e do inverno para o verão. Algumas áreas secas mostram temperaturas mais altas pelo efeito de intensa radiação superficial.
A variação anual de temperatura depende da duração da estação seca. Onde esta não ocorre, a temperatura média mensal pode variar entre 1$2^{\circ} \mathrm{C}$. A energia solar influencia o ciclo hidrológico mais fortemente nos trópicos que em outras regiões do planeta. Em áreas tropicais, a precipitação pluvial é o principal fator determinante do ciclo hidrológico e sua a quantidade e distribuição temporal são os critérios mais importantes para o reconhecimento das subzonas climáticas: úmida $(>1800 \mathrm{~mm})$, úmida-seca $(700-1800 \mathrm{~mm})$ e seca $(<700 \mathrm{~mm})$. O enfoque deste trabalho será feito nos rios que atravessam as sub-zonas tropicais úmidas e úmidos-secos incluindo as monçonicas.

A convergência da circulação das massas de ar dos anticiclones subtropicais para o Equador é denominada de Zona de Convergência Intertropical (ITCZ). A ITCZ é caracterizada pela anulação de efeitos opostos nos padrões de ventos alísios (Balek, 1983). Em ambos os lados da ITCZ é bastante típica a reversão de direção dos ventos com mudanças na umidade e temperatura. $\mathrm{O}$ movimento zenital do sol produz a migração anual da ITCZ para o norte e para o sul, o que, por sua vez, regula o clima tropical úmido. Durante o verão do hemisfério norte, o centro da ITCZ move-se para latitudes entre 100 e 200 norte, com movimentação aproximadamente simétrica para o sul no inverno. A maior amplitude de movimento dá-se sobre a África e a porção oriental do oceano Índico, onde a ITCZ move-se entre o trópico de Câncer em julho e o trópico de Capricórnio em janeiro (Fig. 1).

Em geral, a flutuação da precipitação nas regiões tropicais é relativamente estável comparada àquela não tropical, exceto nas regiões dominadas pelas monções ou por condições orográficas. Climas tropicais úmidos são caracterizados por temperaturas que oscilam entre 24 e $30^{\circ} \mathrm{C}$, com uma amplitude anual de cerca de $3^{\circ} \mathrm{C}$.

A precipitação típica nos trópicos úmidos é de $2000 \mathrm{~mm} / \mathrm{ano}$. Contudo, algumas áreas a precipitação pode atingir $10.000 \mathrm{~mm} /$ ano na floresta de Chocó na Colômbia ou chegar a $14.500 \mathrm{~mm} / \mathrm{ano}$, como a registrada em Monte Camarão na África ocidental (Hidore \& Oliver, 1993). A freqüência e intensidade da precipitação são também variáveis nas regiões tropicais. Em Duitenzorg, Java, chove anualmente 322 dias, ao passo que em Rio Branco (AC), na Amazônia Ocidental brasileira, ocorre uma precipitação de apenas $100 \mathrm{~mm}$ para o período correspondente aos meses de junho, julho e agosto.

A vegetação das áreas tropicais úmidas compreende basicamente as florestas ombrófilas. A distribuição das florestas é também regulada pela migração da ITCZ. Onde esta atinge sua distância máxima, a floresta pluvial é menor, ocorrendo aí outros tipos de unidades transicionais de vegetação. A altitude, por sua vez, é também um importante fator de controle na 


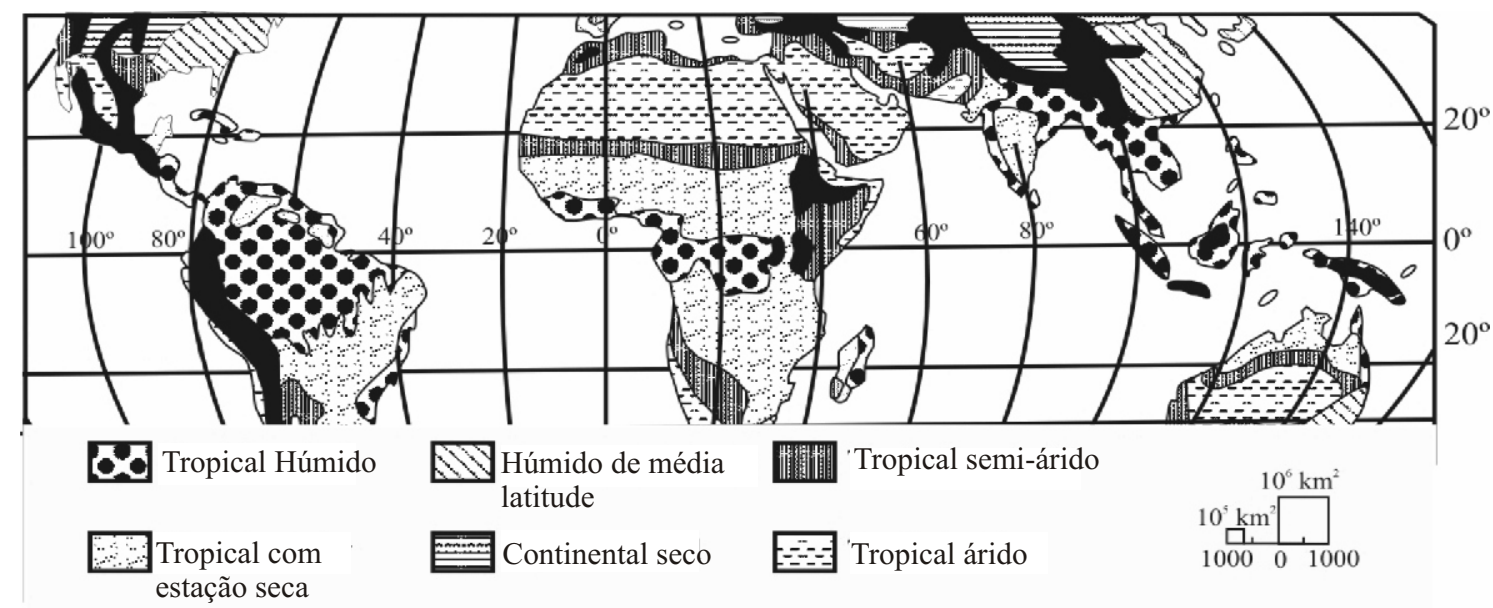

Figura 1-Zonas climáticas nos trópicos .

distribuição da floresta pluvial, uma vez que a temperatura diminui com o aumento da altitude. As florestas pluviais desenvolvem-se geralmente até $1000 \mathrm{~m}$, sendo que em áreas de maior altitude a vegetação é formada por árvores baixas e menos diversificadas.

Climas tropicais úmidos-secos são caracterizados por um padrão sazonal de umidade bastante variado. As áreas de clima tropical úmidoseco ocorrem na periferia dos cinturões de florestas tropicais pluviais. Cerrado, Lhanos e Chaco são áreas características desse tipo de clima na América do Sul. Outras áreas como a região periférica à bacia do Congo, grande parte do sudeste da Ásia e parte das ilhas do Pacífico são também reconhecidas como pertencentes ao extenso cinturão de clima tropical úmido-seco. A alternância de massas de ar marinhas e continentais dominam as estações nesse tipo de clima. A média anual de precipitação varia de local para local, com uma tendência geral de aumento da sazonalidade à medida que se afasta do Equador, atingindo o máximo nas áreas dominadas pelas monções. A convergência das monções úmidas e quentes e o ar continental quente e seco produzem uma maciça condensação da ITCZ sobre a superfície continental quente, que resulta na precipitação de monções. Em Rangoon, Burma, a precipitação média durante os três meses de inverno é de $25 \mathrm{~mm}$, ao passo que durante o verão atinge $1800 \mathrm{~mm}$. Valores extremos de sazonalidade são observados em Cherrapunji, NE da Índia, com $4050 \mathrm{~mm}$ de precipitação em apenas cinco dias durante a monção, para uma precipitação total de $25 \mathrm{~mm}$ para todo inverno (Hidore \& Oliver, 1993). As chuvas monçônicas afetam também grande parte da Índia, Malásia, Tailândia, Vietname, sudeste de Sri Lanka, costa oeste de Burma, norte da Austrália e Serra Leoa (Balek, 1983).

\section{Arcabouço geológico e geomorfológico das bacias hidrográficas tropicais}

Os rios tropicais drenam por todo o planeta uma variedade de províncias geológicogeomorfológicas como os cinturões orogenéticos, os platôs/plataformas sedimentares e basálticas, as áreas cratônicas, as planícies em bacias sedimentares, e os terrenos mistos (Tab. 1, fig. 2).

Os cinturões orogenéticos são feições lineares geradas principalmente no Cenozóico por convergência de placas tectônicas. Caracterizamse por relevo alto, atividade sísmica intensa e, em alguns casos, vulcanismo e plutonismo. Em áreas tropicais estas regiões compreendem parte da cordilheira do Andes na América do Sul, o Himalaia e as ilhas em arco de Sunda e Nova Guiné. Antigos cinturões mesozóicos e paleozóicos reativados incluem-se também nessa categoria.

Os platôs e plataformas são formados pelas bacias sedimentares paleozóicas e mesozóicas no norte e centro do Brasil, o platô Dacan na Índia e os platôs basálticos na África central. Os platôs são áreas relativamente estáveis, que sofreram, levantamentos durante o Cenozóico, sendo, em sua maior parte, constituídos de rochas sedimentares sub-horizontais e extensos terrenos basálticos originados por derrames de lavas.

Por sua vez, são áreas de elevação baixa a moderada, formadas por rochas plutônicas e metamórficas de idade pré-cambriana, caracterizadas por ausência de cobertura sedimentar expressiva. Nesse grupo se encontram os escudos Brasileiros e da Guianas na América do Sul, o embasamento cristalino da Índia peninsular e a porção norte da Austrália.

As planícies das bacias sedimentares cenozóicas constituem as áreas de bacias interiores 


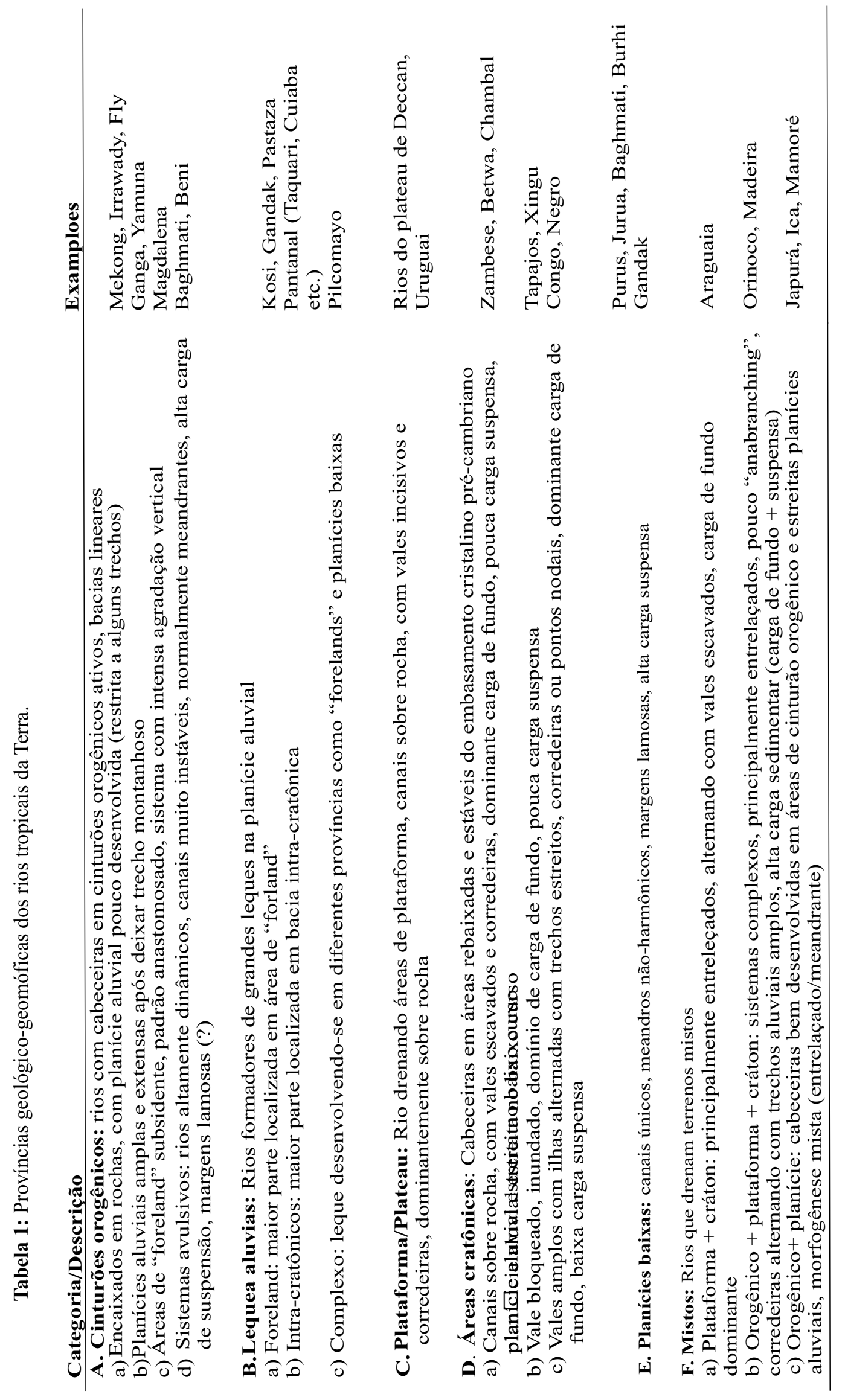




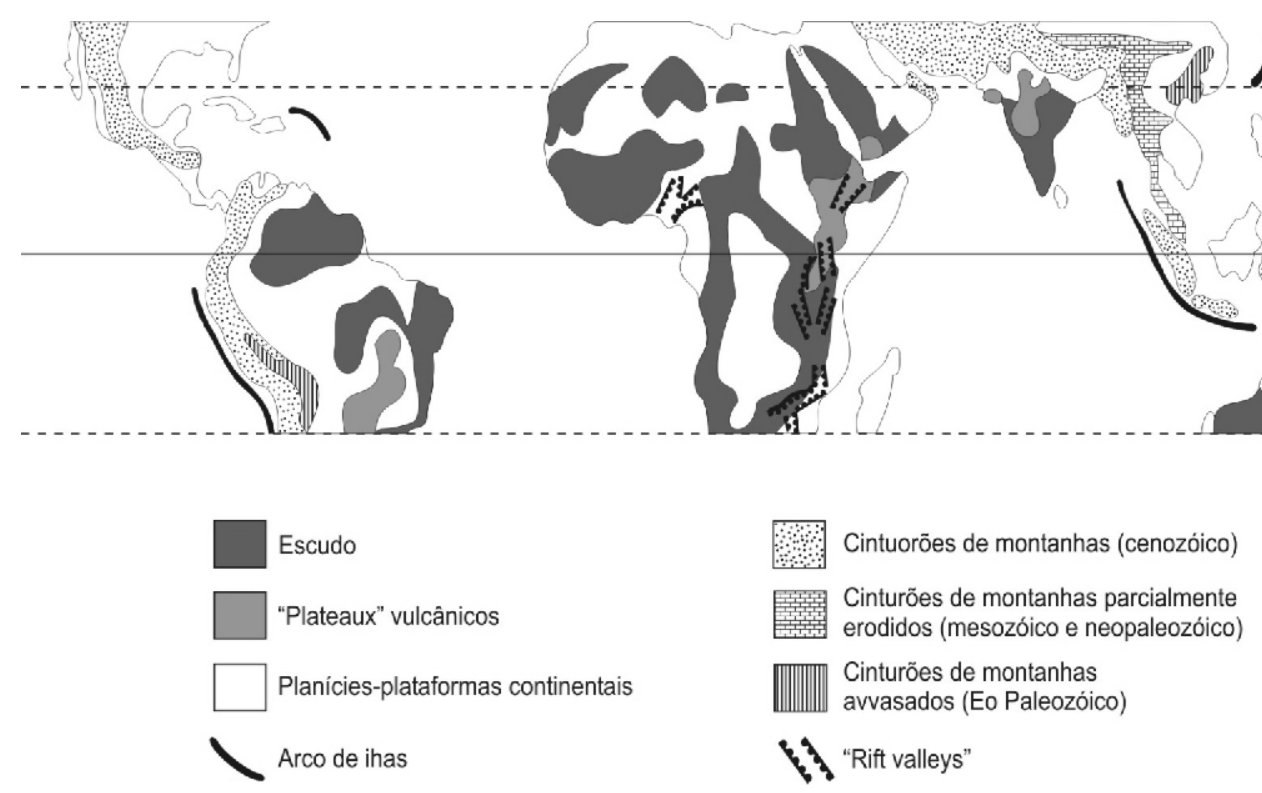

Figura 2. Principais regiões morfotectônicas do planeta.

ativas ("foreland basins") associadas aos cinturões orogênicos. Em regiões tropicais se encontram as bacias associadas aos Andes na América do Sul, a planície indo-gangética, a planície da bacia sedimentar cenozóica da Amazônia (Depressão Ocidental da Amazônia), o platô Oriental da Amazônia e o platô central Africano, na bacia do Congo.

Contudo, grandes rios cortam geralmente mais de uma província geológico-geomorfológica. O rio Amazonas, por exemplo, drena áreas do cinturão orogênico dos Andes, as bacias interiores e áreas da planície do Chaco. Tais sistemas são incluídos na categoria de terrenos mistos.

\section{Hidrologia de rios tropicais}

Oito entre os dez maiores rios do mundo são rios tropicais, sendo que dentre estes, o Negro, o Madeira e o Japura são afluentes do rio Amazonas. Neste trabalho foram considerados apenas os rios tropicais com área de drenagem superior a 10.000 $\mathrm{km} 2$ e com precipitação maior que $700 \mathrm{~mm} /$ ano (Tab. 2), não tendo sido incluídos alguns grandes sistemas fluviais como o Niger e o São Francisco por ocorrerem em área tropical seca. Por outro lado, algumas bacias menores foram aqui abordadas pela sua importância na produção e transferência de sedimento para o oceano.

Devido à grande complexidade do clima tropical e a imensa extensão das bacias de rios tropicais, é impossível estabelecer um único regime para esses rios. Muitos autores propuseram diferentes classificações para regimes de rios tropicais com base na distribuição da precipitação (de verão e de outono): rios pluviais, glaciais e de regime misto (Balek, 1983).

Em geral, rios que drenam as florestas pluviais tropicais como o Purus, Madeira, Negro, Mecong e Irrawady, têm comportamento aproximadamente semelhante àqueles de savana tropical úmida-seca e com os monçônicos. Todos exibem alto pico de descarga, todavia variável durante a estação chuvosa, e baixa vazão quando a precipitação diminui. Alguns rios tropicais como o Congo, Ogooue e o Madalena mostram dois picos anuais de descarga, sendo um principal e outro secundário. A figura 3 apresenta hidrogramas das descargas médias mensais (normalizadas em relação a Qmédia) de alguns grandes rios tropicais. Os rios encontram-se agrupados em (a) rios com descargas altas e baixas bem definidas, em concordância com os períodos chuvosos uni-modais, como, por exemplo, os rios Godavari, Mekong e Ganges; e (b) rios com dois picos por ano, de acordo com os períodos chuvosos bi-modais no verão (principal) e no outono (secundário) como o Madalena, Congo e Purus.

Caracterizou-se a variabilidade da descarga de sistemas fluviais tropicais utilizandose da razão entre a máxima e a mínima descarga diária (Qmax/Qmin), baseando-se nos dados históricos disponíveis. O clima monçônico na Índia é caracterizado por alta variabilidade de descarga, com um período de alto pico de inundação durante a monção de verão e descarga muito baixa durante os meses restantes. Muitos rios da planície gangética mostram incrementos de 40 a 50 vezes na descarga durante as monções com relação à descarga dos outros meses (Sinhá \& Firend, 1994, Sinhá \& Jain, 1998). Ao contrário do que normalmente se imagina, alguns rios da floresta pluvial tropical apresentam também uma marcante variabilidade, semelhante aos de ambientes de savana. Rios tropicais pluviais 
Tabela 2. Principais rios tropicais do mundo (rios drenando os trópicos secos não forma incluidos).

\begin{tabular}{|c|c|c|c|c|c|}
\hline Rio & País da foz & $\begin{array}{c}\text { Descarga } \\
\text { media annual } \\
\left(\mathrm{m}^{3} / \mathrm{s}\right)\end{array}$ & $\begin{array}{c}\text { Área de } \\
\text { drainagem } \\
\left(10^{3} \mathrm{~km}^{2}\right)\end{array}$ & $\begin{array}{c}\text { Qs anual } \\
\left(10^{6} \text { ton/ano }\right)\end{array}$ & $\begin{array}{c}\text { Suprimento } \\
\text { sedimkentar } \\
\text { (ton } / \mathrm{km}^{2} / \mathrm{ano} \text { ) }\end{array}$ \\
\hline Amazonas ${ }^{1}$ & Brasil & $209000^{\mathrm{a}}$ & 6000 & $1000^{b}$ & 167 \\
\hline Congo $^{2}$ & Zaire & 40900 & 3700 & $32.8^{\mathrm{c}}$ & 9 \\
\hline Orinoco $^{3}$ & Venezuela & $35000^{b}$ & 950 & $150^{b}$ & 157.8 \\
\hline Madeira $^{1}$ & Brasil & $32000^{\mathrm{a}}$ & 1360 & $450^{h}$ & 330 \\
\hline Negro $^{1}$ & Brasil & $28400^{a}$ & 696 & $8^{a}$ & 11.5 \\
\hline Brahmaputra & Bangladesh & 20000 & 610 & 520 & 852.4 \\
\hline Japura $^{1}$ & Brasil & $18600^{\mathrm{a}}$ & 248 & $33^{a}$ & 133 \\
\hline Paraná & Argentina & $18000^{\mathrm{k}}$ & 2600 & $112^{\mathrm{k}}$ & 43 \\
\hline Mekong & Vietnam & 14900 & 810 & $160^{c}$ & 197.5 \\
\hline Irrawady & Myammar & 13600 & 410 & $260^{c}$ & 634 \\
\hline Tapajos $^{1}$ & Brasil & $13500^{\mathrm{a}}$ & 490 & $6^{a}$ & 12.2 \\
\hline Ganges & Índia & 11600 & 980 & 524 & 534.7 \\
\hline Tocantins $^{4}$ & Brasil & 11800 & 757 & 58 & 76.6 \\
\hline Kasai $^{2}$ & Zaire & 11500 & 861.8 & - & - \\
\hline Purus $^{1}$ & Brasil & $11000^{\mathrm{a}}$ & 370 & $30^{\mathrm{a}}$ & 81 \\
\hline Marañón ${ }^{1}$ & Peru & $10876^{\mathrm{e}}$ & 407 & $102.4^{\mathrm{e}}$ & 251.6 \\
\hline Oubangui $^{2}$ & Congo & $9900^{j}$ & 550.7 & - & - \\
\hline $\mathrm{Xingu}^{1}$ & Brasil & $9700^{\mathrm{a}}$ & 504 & $9^{a}$ & 17.8 \\
\hline Ucayali $^{1}$ & Peru & $9544^{\mathrm{e}}$ & 406 & $124,6^{\mathrm{e}}$ & 306.9 \\
\hline Salween & Brasil & 9510 & 325 & $100^{c}$ & 307.7 \\
\hline $\begin{array}{l}\text { Madre de } \\
\text { Dios/Beni }^{1}\end{array}$ & Brasil/Bolivia & 8920 & 282.5 & 165 & 584 \\
\hline Ica $^{1}$ & Brasil. & $8800^{\mathrm{a}}$ & 143.7 & 19 & 132.2 \\
\hline Jurua $^{1}$ & Brasil & $8440^{a}$ & 185 & $35^{a}$ & 189.2 \\
\hline Mamoré $^{1}$ & Brasil/Bolívia & $8255^{a}$ & 589.5 & $80^{a}$ & 135.7 \\
\hline Guaviare $^{3}$ & Venezuela & $8200^{f}$ & 114.2 & $30^{f}$ & 678.3 \\
\hline Magdalena & Codkmbibia & $7200^{g}$ & 257 & $144^{\mathrm{g}}$ & 544.7 \\
\hline Zambezi & Mozambique & 6980 & 1400 & 48 & 34.3 \\
\hline Araguaia $^{4}$ & Brasil & 6100 & 377 & 18 & \\
\hline Caroni & Venezuela & $5000^{f}$ & 93.5 & $2^{f}$ & 21.3 \\
\hline Fly & Nova Guiné & 4760 & 64.4 & $70^{j}$ & 1087 \\
\hline Uruguay & Argentina/Uruguai & 4660 & 365 & 6 & 16.4 \\
\hline $\mathrm{Meta}^{3}$ & Venezuela & $4600^{f}$ & 105.4 & $80^{\mathrm{f}}$ & 759 \\
\hline Napo $^{1}$ & Peru & 4595 & 122 & $22.4^{\mathrm{e}}$ & 183.6 \\
\hline Caura $^{3}$ & Venezuela & $4000^{f}$ & 47.3 & $2^{f}$ & 42.2 \\
\hline
\end{tabular}

${ }^{\mathrm{a}}$ Filizola, 1999; ${ }^{\mathrm{b}}$ Meade et al., 1983, 'Meade, 1996, ${ }^{\mathrm{e}} \mathrm{Gibss}, 1967$;; ${ }^{\mathrm{f}}$ Nordin et al,1994; ${ }^{\mathrm{g}}$ Restrepo and Kjferve,2000; ${ }^{h}$ Martinelli et al,1993; ${ }^{j}$ Milliman et al,1999; ${ }^{\mathrm{k}}$ Amsler et. al, 2000.

${ }^{1}$ Rios da bacia do Amazonas; ${ }^{2}$ Rios da bacia do Congo, ${ }^{3}$ Rios da Bacia do Orinoco, ${ }^{4}$ Rios da bacia do Tocantins/Araguaia. 

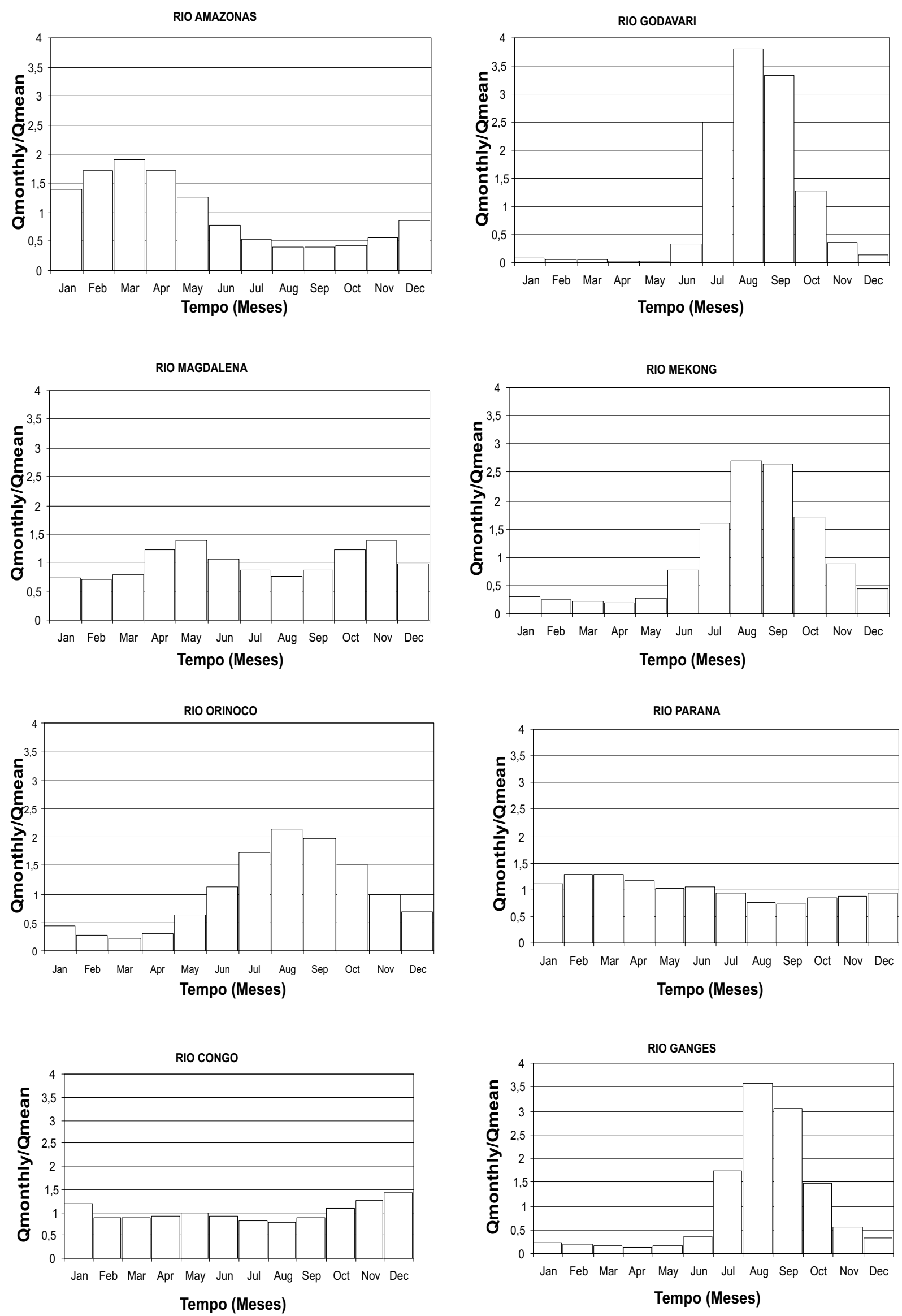

Figura 3. Histogramas das descargas médias mensais - Q mensal (normalizadas pela descarga média do período analisado - Q média) durante o ano. 
como o Purus e Juruá mostram valores de variabilidade de descarga superiores àqueles que drenam áreas de savana como o Tocantins, ou de ambientes mistos como o Madalena ou Paraná.

Embora a razão entre a descarga máxima e a descarga média das cheias anuais (Qmax/Qmaf) seja mais comumente utilizada para caracterizar regimes de cheias, optou-se neste trabalho por utilizar-se da razão entre a descarga máxima anual e a descarga média anual (Qmax/Qmean), devido à disponibilidade de dados. Do diagrama Qmax/Qmean versus Qmax/Qmin (Fig. 4) pode-se obter as seguintes considerações:

1. Os rios com alta variabilidade de descarga (Qmax/Qmin) também correspondem àqueles de alto regime de cheia, caracterizados por altos valores de Qmax/Qmean. Considerando, contudo, que apenas os sistemas fluviais com área de drenagem superior a $10.000 \mathrm{~km} 2$ foram incluídos nesta análise, é interessante notar que a área de drenagem não é um fator primário no controle da variabilidade de fluxos e cheias extremas.

2. As bacias de drenagem em florestas pluviais mostram geralmente valores baixos tanto de Qmax/Qmean como de Qmax/Qmin, com aumento marcante para os rios de domínio de savana. O grupo intermediário inclui também grandes bacias de drenagem tropicais complexas com mais de uma zona climática como as do rio
Orinoco, Madeira, Tocantins e Brahmaputra e mostram uma tendência semelhante a das bacias que envolvem mais de um cinturão climático em áreas temperadas da Europa Ocidental, Sibéria e os sistemas fluviais do norte da América do Norte (Canadá e Alasca).

3. Descargas com maior variabilidade são observadas nos sistemas de clima árido a semi-árido, que mostram altos valores de Qmax/Qmin. Sistemas de áreas extremamente áridas não foram incluídos nesta análise, uma vez que a descarga mínima é, em muitos casos, igual a zero.

4. Os rios tropicais perenes como os procedentes dos Andes para a planície do Chaco exibem altos valores de Qmax/Qmean entre 150 (Pilcomayo) e 190 (Bermejo). Na realidade, esses rios cortam áreas de florestas montanhosas da zona sub-andina e semi-árida do Chaco, resultando numa descarga extremamente variável.

5. Regimes mais extremos são encontrados nos sistema de monções da Índia peninsular. Durante as monções de verão, os rios dessa região apresentam picos de descarga extremamente altos quando comparados com descargas baixas para o resto do ano. Os rios da Índia peninsular aparecem muito distantes dos outros sistemas fluviais devido essa característica.

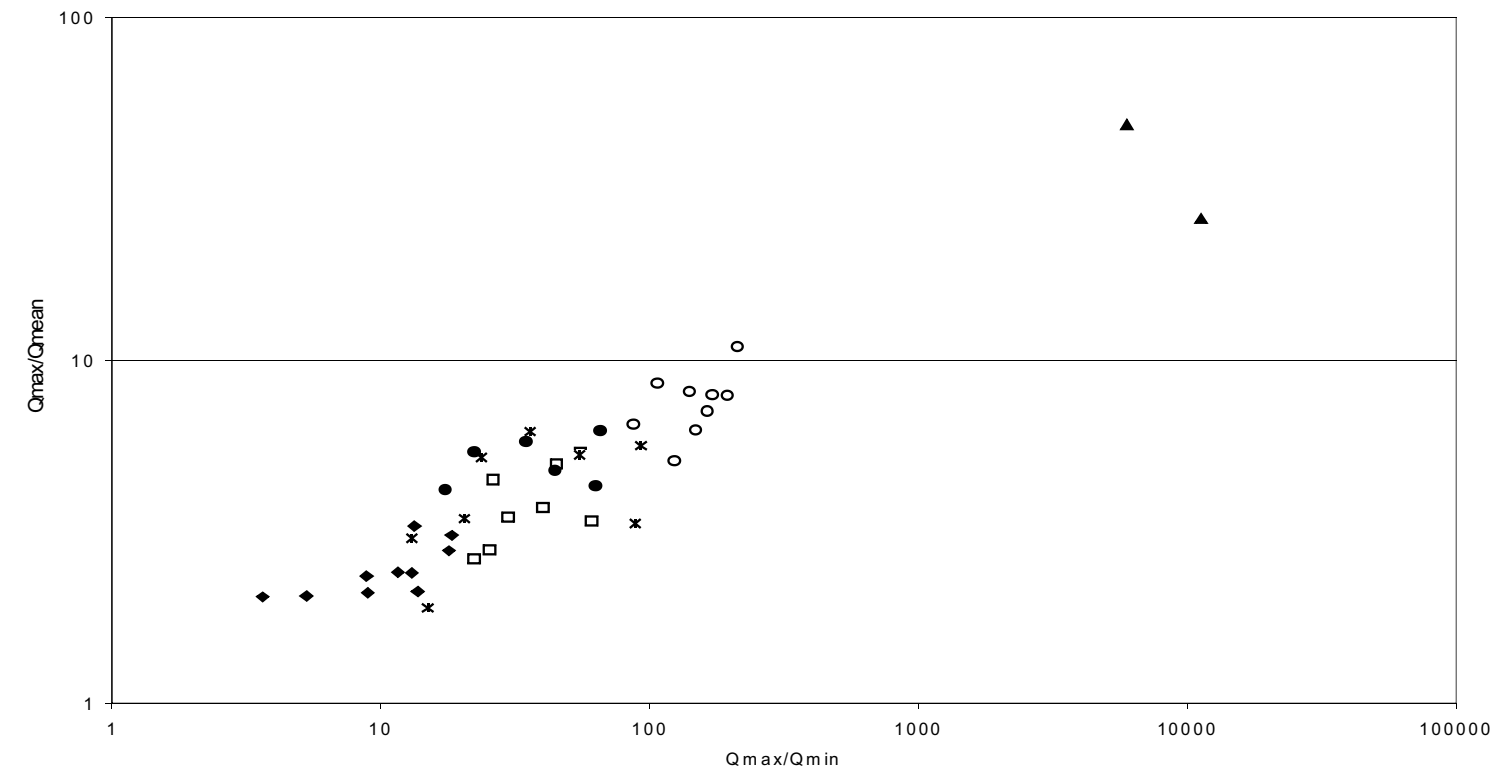

- Floresta pluvial =Congo, Juruá, Madeira, Purus, Magdalena, Alto Paraná, Ogooue, Irrawady, Brahmaputra

$\square$ Úmido-seco:=Mamoré, Orinoco, Tocantins, Sanaga, Uruguay, Alto Xingu, Araguaia, Ganges

$\Delta$ Índia peninsular monçônica $=$ Narmada, Godavari

$\bigcirc$ Semiárido = Douro, Colorado (Texas), Ebro, Colorado (Arizona), Pilcomayo, Trinity, Murray, Bermejo, Grande Santiago

* Taiga/Tundra= Obi, Colúmbia, Mc Kenzie, Nelson, Yenisei, Pékora, Amur, Lena.

- Temperado = Dnepr, Seine, loire, Vistula, Dvina, Volga

Figura 4- Variabilidade de descarga em rios de diferentes zonas hidrológicas/morfoclimáticas (para grandes bacias foi considerado o clima dominante). Na abscissa (x) foi lançada a razão Qmax/Qmin (razão das descagas diária maxima e mínimae Qmax/Qmin para a série histórica disponível) e na ordenada (y) foi lançada a razão Qmax/Qmédio (a razão entre a discarga máxima diária e a descarga média anual para a mesma série histórica) 
Os regimes de rios tropicais são também afetados pela recorrência de 2-7 anos dos eventos do El Ninõ (ENSO). Estudos efetuados por Molion \& de Mares (1987) e Richey et al. (1989) demonstraram que a descarga anual dos rios amazônicos e da bacia do Congo correlacionam-se fraca ou mesmo negativamente com as anomalias da temperatura de superfície do oceano Pacífico (SST) com uma variação de $10 \%$ na descarga anual produzida pelo ENSO (Amarasekera et al., 1997). Por outro lado, na bacia do Paraná, as descargas dos rios mostram uma relação positiva que pode aumentar tanto a magnitude quanto a duração das cheias (Depetris \& Kempe, 1990, Paoli \& Schreider, 2000; Paoli \& Cacik, 2000). O sistema asiático de monções está também fortemente relacionado com os eventos do ENSO. Muitas das grandes cheias da Índia peninsular estão relacionadas com o aumento da precipitação das monções e a eventos frios do ENSO (Kale, 1999, Hire, 2000).

\section{Transporte de sedimentos}

As bacias de relevo alto em cinturões orogênicos ativos têm alta produção de sedimentos. Os rios que drenam o cinturão orogênico sul-asiático e ilhas do oceano Índico oriental são responsáveis por mais de $70 \%$ da carga sedimentar transportada aos oceanos (Milliman \& Made, 1983). As ilhas de Sumatra, Java, Borneo, Cebeles e Timor constituem pequenas bacias de topografia acentuada, com substrato de rochas jovens e erodíveis, situadas num clima tropical úmido. Com essas características, mesmo compreendendo apenas $2 \%$ da área emersa drenada do planeta, descarregam anualmente 4200 milhões de toneladas de sedimentos, ou seja, cerca de 20 a $25 \%$ da carga total de sedimentos transferida anualmente aos oceanos (Milliman et al., 1999). Os rios dos Himalaias indús transportam também uma grande quantidade de sedimentos (Fig. 5). As bacias maiores como as do Brahamaputra e Ganges são as que mais produzem sedimentos no mundo, transferindo anualmente 900 a 1200 milhões de toneladas ao oceano. Bacias menores como as do Kosi e Gandak, por exemplo, têm uma produção de sedimento de 190 e 80 milhões de toneladas por ano.

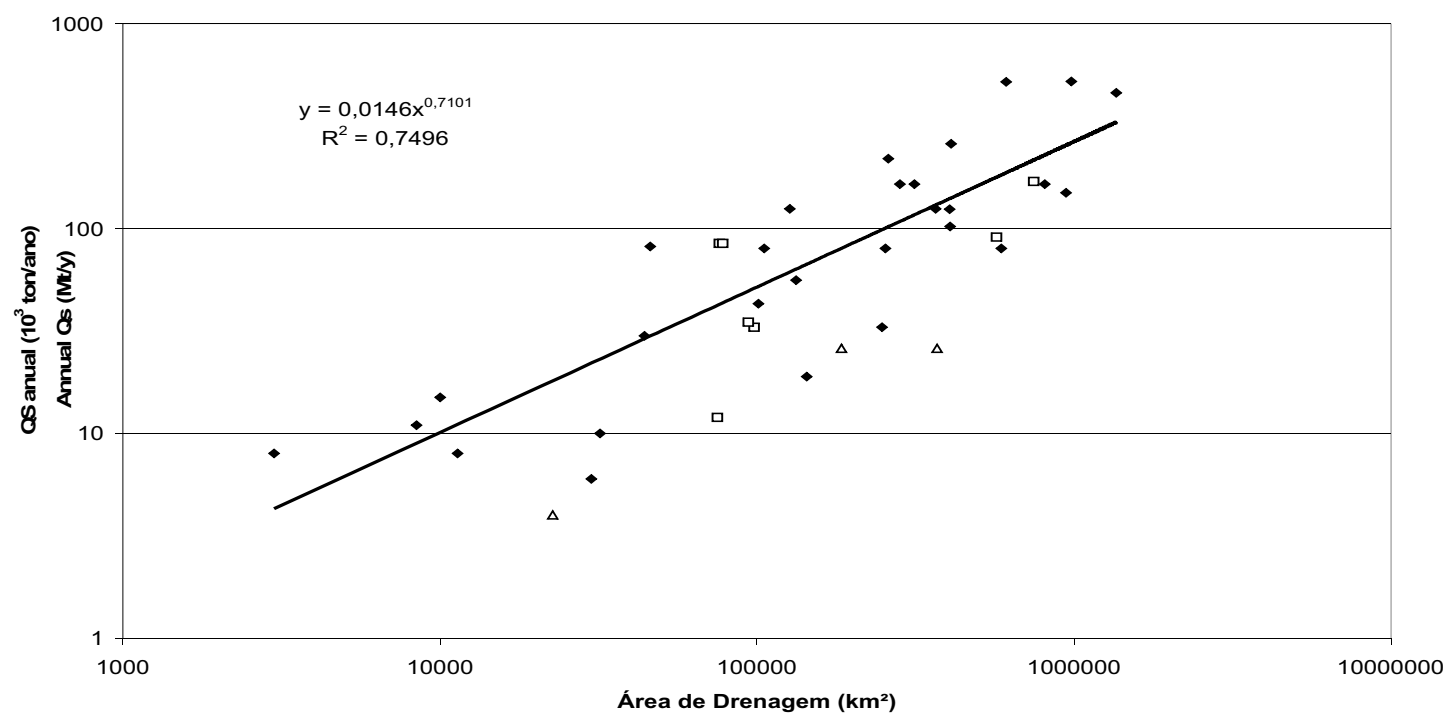

Rios orogênicos continentais $\boldsymbol{=}$ Ganges, Brahmaputra, Buhri Gandak, Kamla-balam, Mahakam, Yamuna, Gomti, Ramganga, Gandak, Kosi, Baghmati, Gahghra, Mekong, Irrawady, Madeira,Mamoré, Beni-Madre de Dios, Japurá, Içá, Ucayali, Marañón, Orinoco, Meta, Guaviare, Bermejo, Magdalena.

Rios da Ásia insular $\square$ Fly, Mahakam, Sepik, Java, Borneo, Celebes and New Guinea (suma por ilha)

Rios meandrantes de planície (Sudeste amazônico) $\triangleq$ Purus, Juruá, Acre

Figura 5. Carga suspensa anual (Qs) versus área de drenagem. A correlação é positiva para rios em áreas orogênicas continentais. Notar que muitos rios orogênicos continentais ficam acima dos rios insulares asiáticos (que é considerada uma área planícies sedimentares totalmente coberta pela floresta e também produzem abundante carga sedimentar.altamente prudutora de sedimento) e os rios de planície do sudoeste Amazônico que drenam.

A produção de sedimento é também bem alta nos Andes sul-americanos. A bacia do rio Madalena, com uma área de $257.000 \mathrm{~km} 2$, transfere anualmente entre 144 e 220 milhões de toneladas procedentes dos Andes colombianos para o mar do Caribe (Milliam \& Made, 1983; Restrepo \& Kjerfve, 2000; Winkley et al., 1994). Drenando os Andes bolivianos e peruanos, os tributários do rio Madeira têm uma alta carga de sedimento suspenso e são importantes fornecedores de sedimento à bacia do Amazonas. A bacia desse tributário contribui com 
$50 \%$ do total da carga de sedimentos suspensos transportados pelo rio Amazonas, com valores estimados entre 248 a 600 milhões de toneladas por ano (Meade, 1994; Meade et al., 1983; Martinelli et al., 1993, 1998; Filizola, 1999). A carga sedimentar do rio Beni, por exemplo, é estimada em 165 milhões de toneladas anuais, enquanto o rio Mamoré contribui com 65 milhões de toneladas por ano (Guyoy et al., 1999). Assim, mais de $90 \%$ do total da carga sedimentar do sistema do Amazonas, estimada em cerca de 1000 milhões de toneladas/ano, provem de seus tributários andinos.
Os rios insulares da Ásia apresentam valores semelhantes ou ligeiramente inferiores dos rios orogênicos da América do Sul e da Ásia quando comparados pela relação entre fornecimento de sedimento e a descarga líquida de (Fig. 6). Isso se deve provavelmente ao relevo menos acentuado dessa área em comparação com os Himalaias e os Andes. Contudo, os dados disponíveis estão em concordância com os resultados obtidos por Milliman et al. (1999), que estabelecem uma boa correlação entre os valores de fornecimento de sedimento dos rios insulares com aqueles do sudeste asiático.

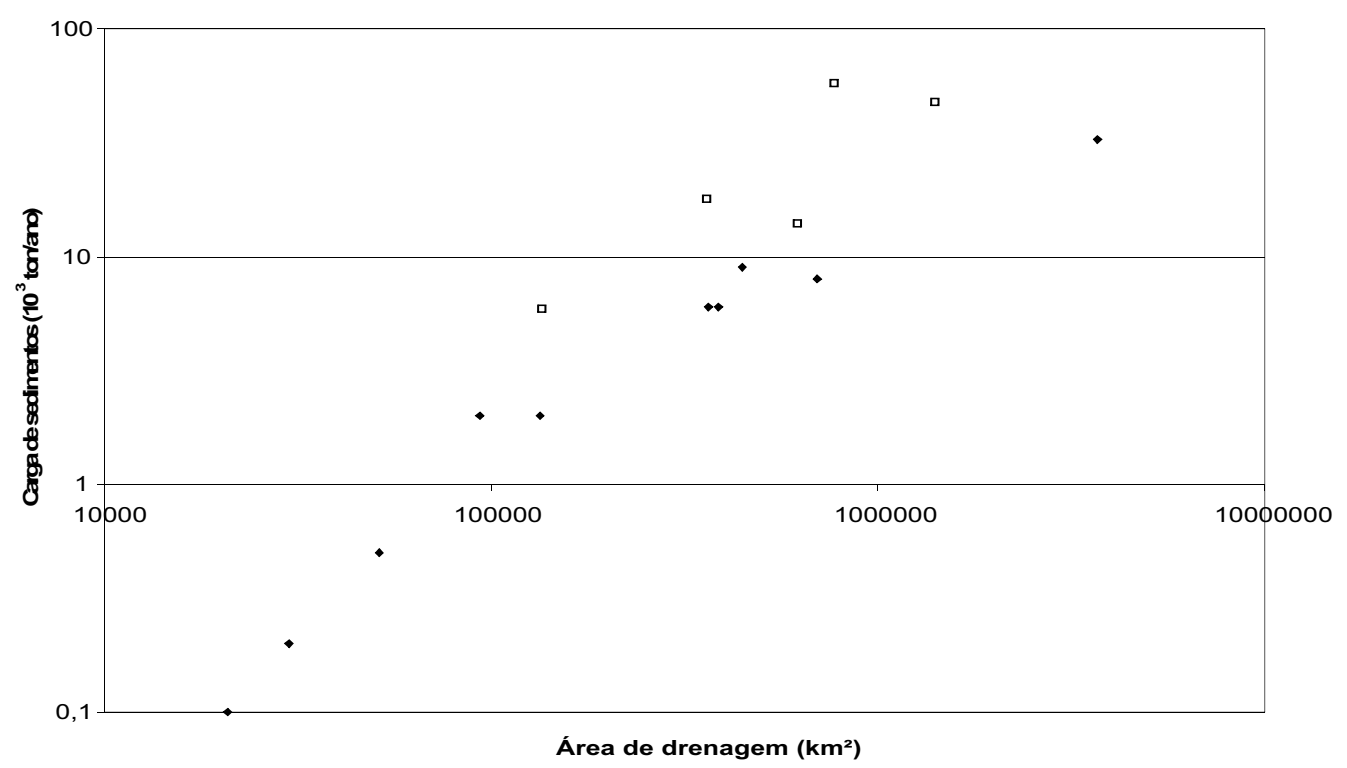

Figura 6. Rios de platô/cratônicos de clima úmido-seco e da floresta amazônica: Carga suspensa anual (Qs) versus área de drenagem. $\downarrow$ Regime dominado pela floresta pluvial = Congo, Tapajós, Trombetas, Negro, Purus Jarí, Purua. Uruguay $\square$ é dominado por regime úmido-seco (vegetação mista, principalmente savana) $=$ Araguaia,, Paraná, Sanaga, Zambese, Tocantins, Xingu.

Os tributários andinos do rio Paraná carregam também grandes quantidades de sedimento suspenso. Com uma descarga anual média de $143 \mathrm{~m} 3 / \mathrm{s}$, o rio Bermejo contribui com cerca de $60 \%$ (48 milhões de toneladas/ano) do total de sedimentos suspensos transportados pelo rio Paraná $(\mathrm{Qmean}=18.000 \mathrm{~m} 3 / \mathrm{s})$. A principal diferença entre os rios insulares asiáticos e os tributários dos sistemas dos Himalaias e Andes é que os primeiros são curtos, com alto gradiente e drenam diretamente para o oceano, enquanto os últimos constituem grandes sistemas fluviais como o Amazonas, Paraná, Orinoco, Madalena, Ganges e Brahamaputra. Em amplas bacias, a carga sedimentar não é totalmente transferida para o oceano, sendo parte dela estocada nas planícies aluviais. Além disso, um grande número de tributários provindos de planícies ou de áreas cratônicas e plataformais têm uma descarga sedimentar muito reduzida quando comparada a sua descarga líquida. A alta produção de sedimentos da região himalaia é favorecida pela chuva de monção nas áreas fonte. Precipitações intensas, chegando aos $11.000 \mathrm{~mm} /$ ano, deflagram uma erosão extensiva a toda bacia de drenagem em dessa forma, introduzem grandes quantidades de sedimento (Froehlich \& Starkel, 1993). Na América do Sul, os Andes atuam como uma barreira para as massas de ar provindas do leste, e assim, incrementam a precipitação ao longo da sua vertente ocidental, da Argentina à Venezuela. O relevo elevado e precipitação altamente concentrada nessa região produzem dessa forma grande quantidade de sedimento. A 
precipitação pode atingir mais de $600 \mathrm{~mm} / \mathrm{ano} \mathrm{em}$ algumas regiões sub-andinas do Equador, Peru e Bolívia.

Os rios que drenam áreas de cráton ou plataforma, tanto em clima tropical úmido como de savana, são caracterizados por um baixo suprimento de sedimentos (Fig. 7). Os imensos sistemas fluviais de áreas de floresta pluvial como os do rio Congo, Negro, Tapajós, Xingu transportam quantidades quase insignificantes de sedimento suspenso, quando comparados com suas imensas áreas de drenagem e a magnitude de suas descargas líquidas. O rio Negro, por exemplo, com uma bacia de drenagem de $65.900 \mathrm{~km} 2$ e descarga média anual de $29.000 \mathrm{~m} 3 / \mathrm{s}$, carrega apenas 8 milhões de toneladas anuais de sedimento suspensos, 50\% constituída de matéria orgânica (Filizolla, 1999). O rio Congo, o segundo maior rio do planeta em termos de descarga líquida (Qmean $=40.000 \mathrm{~m} 3 / \mathrm{s})$, carrega aproximadamente 40 milhões de toneladas de sedimentos por ano (Meade, 1996). Os grandes tributários cratônicos do Amazonas, como os rios Tapajós, Xingu e Trombetas, também carregam insignificantes quantidades de sedimentos suspensos.

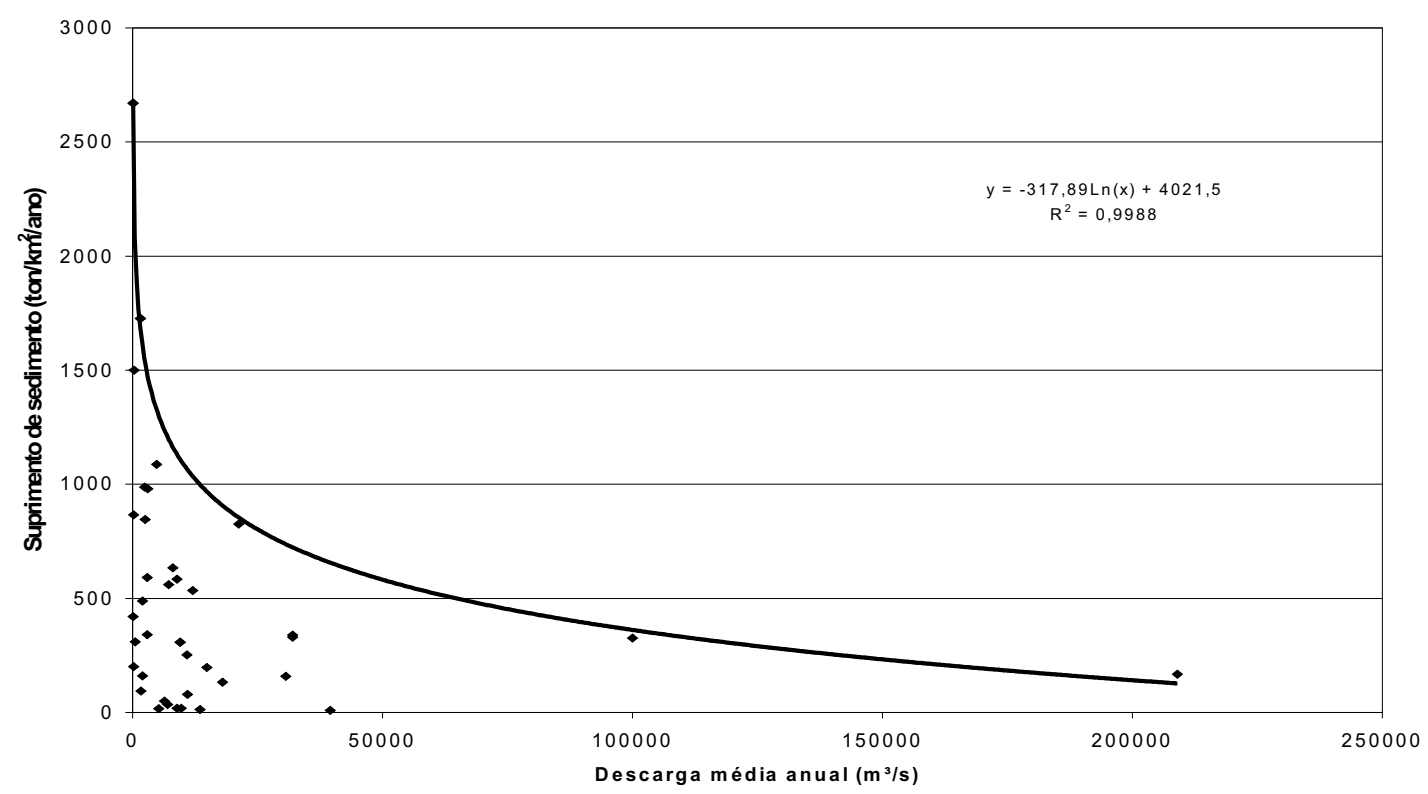

- = Japurá. Madeira, Purus, Araguaia, Magdalena, Orinoco, Paraná, Bermejo, Uruguai, Sanaga, Amazonas (foz), Congo, Irrawady, Amazonas (Manacapurú), Ganges, Brahmaputra, Mekong, Sepik, Fly, Mahakan, Godavari, Buhri Gandak, Kamla-balam, Yamuna, Gomti, Ramganga, Krishna, Gandak, Kosi, Baghmati, Ghaghra.

Figura 7- Suprimento de sedimentos (ton $/ \mathrm{km}^{2}$ ano) versus descarga média anual (Qmean) para rios tropicais. A curva envolvente poderia estar indicando um umbral natural do fornecimento de sedimento em relação com a Qmédia para os rios atuais. Considerando que algumas das bacias com maior suprimento de sedimento no planeta foram incluídas, é provável que essa curva envolvente possa ser usada universalmente com boa aproximação.

Os rios de áreas cratônicas, plataformais ou de diferentes combinações de domínios geológicos em savanas ou savana-floresta, como por exemplo, os rios Toacantins-Araguaia, Paraná e Orinoco, mostram baixa carga sedimentar transportada quando comparados aos rios de montanha, mas altos valores frente aos rios cratônicos ou de plateau em áreas florestadas. O suprimento sedimentar versus a descarga líquida de diversos rios tropicais do planeta indicam, em escala logarítmica, que o suprimento de sedimento é pouco variável nas bacias de tamanho médio, mas decresce rapidamente nas grandes (Fig. 8). Considerando que a descarga líquida está relacionada com a área da bacia, a relação logarítmica é um indicador de um limite natural de suprimento de sedimentos para grandes sistemas fluviais tropicais.

\section{Morfologia do canal}

Rios tropicais têm uma grande variedade de formas de canal. Em muitos casos, e particularmente nas grandes bacias, os rios exibem uma transição de um para outro padrão, o que dificulta, ou mesmo inviabiliza, a aplicação da terminologia tradicional em canais retos, meandrantes e entrelaçados. Pode ser mais apropriada, ainda que em trechos regionais selecionados, a aplicação da terminologia de sistema de canais simples e múltiplos (Friend $\&$ Sinha, 1993) ou sistema de complexos de anastomosamento (Nanson \& Knighton, 1996).

Os rios originados em cinturões orogênicos são caracterizados por uma alta carga suspensa $(>80 \%)$ para uma carga de fundo bastante reduzida (2 a 15\%). Apresentam 

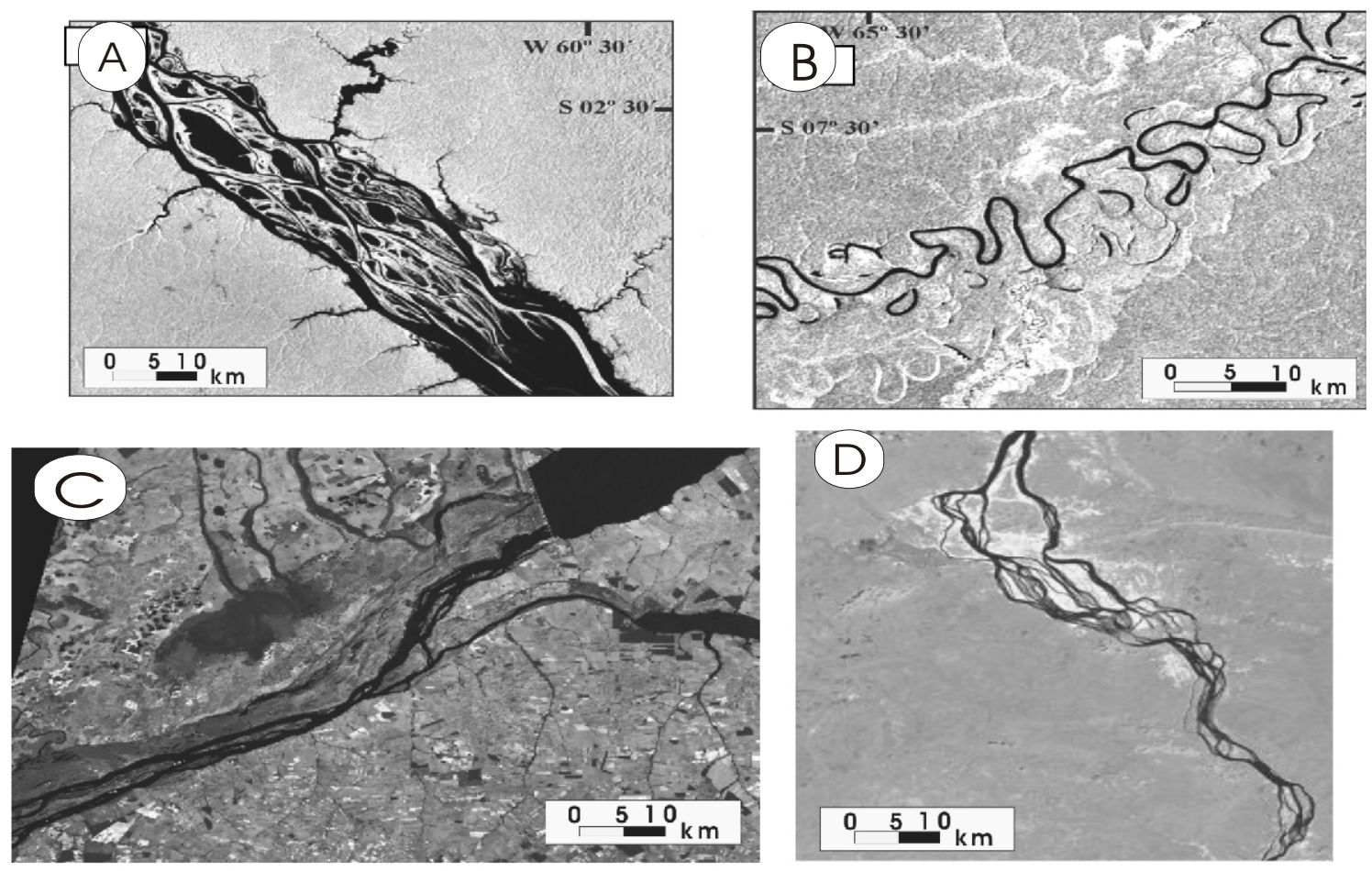

Figura 8- Padrão de canal em rios tropicais a) Negro, b) Purus, c) Parana, d) Mekong, d) leque do Taquar, e) leque do Kosi.

freqüentemente canais sinuosos nos grandes cursos, e podem alternar trechos sinuosos e retilíneos nas drenagens médias e pequenas. Nas florestas pluviais desenvolvem meandros assimétricos e desarmônicos, que, via de regra, mostram profunda incisão gerada durante $o$ Holoceno. Bons exemplos são os rios do sudoeste amazônico como o Purus e o Juruá (Latrubesse \& Kalicki, 2002), e o rio Fly na Nova Guiné (Dietrich et al., 1999). Meandros harmônicos estão geralmente relacionados a rios com carga mista, que, na maioria, drenam áreas de platô como o rio das Mortes (importante tributário da bacia Tocantins-Araguaia) e o rio Paraguai. Esse tipo de padrão é também encontrado em trechos específicos do rio Iça (ou Putumayo), um tributário setentrional do rio Amazonas. Alternância de canais simples e múltiplos foi descrita por Rasanen (1993) no rio Ucayali no Peru. Os rios indianos de Yamuna e Ganges exibem trechos de meandros isolados entre segmentos de canais múltiplos (Sinha et al., 2002). $\mathrm{O}$ rio Brahmaputra apresenta um sistema de canais múltiplos com sinuosidade moderada em determinados trechos (Bristow, 1987; Coleman, 1969). Alguns sistemas fluviais menores da planície gangética, como o rio Baghmati ao norte de Bihar, foram descritos como sistemas anastomosados por apresentarem comportamento hiper-avulsivo, mesmo quando tendo carga sedimentar dominantemente suspensa (Jain and Sinha, 2003b).

Rios que drenam áreas cratônicas e de platô, como o Paraná, Araguaia e outros, têm menor proporção de carga suspensa em relação à de fundo e assim desenvolvem canais com baixa sinuosidade. O rio Paraná, acima da foz do rio Paraguai, por exemplo, exibe um padrão anastomosado com tendência a desenvolver ilhas e transporta $25 \%$ de sua carga total como carga de fundo (Orfeo \& Stevaux, 2002). Os grandes rios de áreas florestadas como o Congo e o Negro desenvolvem uma intrincada morfologia multicanal com um complexo de arquipélagos.

Além do controle hidrológico na morfologia do canal, é importante mencionar dois fatores que controlam a variação espacial e temporal da morfologia de muitos rios, pelo menos localmente: neotectônica e topografia do embasamento. A neotectônica é freqüentemente mencionada como um dos importantes controles da geomorfologia dos cinturões aluviais e dos padrões de canal dos grandes sistemas fluviais do mundo. De fato, grande número de estudos sobre neotectônica utilizou as formas de canal como indicadores de falhas, alçamento e basculamento de blocos (Schumm, 1985). Os rios Amazonas, Brahmaputra, Paraná e outros rios tropicais exibem exemplos claros de trechos controlados tectonicamente (Latrubesse \& Franzinelli, 2002; Fortes et al.,(no prelo); C. Ramonell, com. pess; Schumm et al. 2000). No caso do Brahmaputra, terremotos introduzem grande quantidade de sedimentos que conseqüentemente afeta a morfologia do canal (Goswamy, 1998; Bristow, 
1987). Muitos rios menores da planície do Ganges respondem também ao tectonismo do Himalaia. Movimentos bastante sutis na planície do rio Baghmati provocam freqüentes avulsões, desenvolvimento de meandros compressivos e mudanças locais no gradiente (Jain \& Sinha, 2003b).

Outro fator importante é a topografia do embasamento. Muitos rios, com cobertura sedimentar aluvial relativamente delgada, geralmente têm a morfologia de seus canais afetada pelo substrato rochoso do trecho. Rochas do embasamento restrigem ou dividem o canal e a própria planície aluvial, além de afetar em seu perfil afetarem longitudinal. O complexo das Quatro Mil Ilhas do rio Mecong é um fantástico exemplo de controle do embasamento sobre o padrão de canal. Em rios da porção meridional da planície do Ganges, como o Ken e Son, pode-se encontrar trechos da planície aluvial fortemente controlados pela exposição ou sub-exposição do substrato rochoso.

\section{Processo, morfologia e estratigrafia fluvial}

Os modelos atuais usados para o entendimento de seqüências sedimentares antigas são pobres e incompletos (Miall, 1996), principalmente no que concerne aos sistemas fluviais tropicais. Muitos desses sistemas são grandes e registram intervenção eólica em sua história quaternária. Na planície indo-gangética e no Chaco, por exemplo, podem ser observados depósitos fluviais com grande influência eólica durante o Quaternário Superior. Também no sistema do rio Orinoco (Nordin et al, 1994; Nordin \& Perez Hernandez, 1989) e no Paraná superior (Stevaux, 2000) foi identificada atividade eólica relacionada a seus grandes cinturões aluviais.

Avulsão é um dos maiores processos fluviais atuantes em rios tropicais. Avulsões típicas em trechos específicos de grandes rios da bacia amazônica como o Solimões, Moa, Ipixuna, nos rios da depressão de Ucamara (Latrubesse \& Franzinelli, 2002, Latrubesse \& Rancy, 2000, Mertes et al., 1996, Dumont, 1993) e da bacia de Beni (Dumont \& Fournier, 1994, Parsinnen et al., 1996) estão relacionadas a neotectonismo. Os rios da planíce indo-gangética são os mais dinâmicos no mundo em termos de rapidez e freqüência de avulsões. O rio Kosi migrou cerca de $100 \mathrm{~km}$ para oeste nos últimos 200 anos (Leopold \& Maddock, 1953; Mookerjea, 1961; Gole \& Chitale, 1966; Arogyawami, 1971; Wells \& Dorr, 1987; Agrawal \& Bhoj, 1992). A migração do rio Gandak, embora mais lenta, foi bastante expressiva, com cerca de $80 \mathrm{~km}$ para leste em 5000 anos (Mohindra et al., 1992). Outros rios inter-leques de menor porte do norte da planície de Bihar, como o Burhi, Bagnati e Kamla-Balan mostram também atividade de processos de avulsão e corte (Phillip et al., 1989, 1991; Sinha, 1996). Numa das mais didáticas reconstruções da dinâmica fluvial dessa região, Jain \& Sinhá (2003b) demonstram a variação em décadas das avulsões durante os últimos
250 anos. Os maiores fatores de controle para tais avulsões são o próprio ajuste sedimentológico como também o neotectonismo. Mais para oeste, na planície indo-gangética, os rios não são tão dinâmicos como os do norte de Bihar. Contudo, foram registrados movimentos de canal no rio Ganges em Kanpur (Hegde et al., 1989), e nos rios Ghaghra Sarda e Rapti próximos de Bahraich (Tangri 1986; Chandra, 1993).

Grandes leques são também característicos de sistemas tropicais. Alguns leques situados em cinturões orogenéticos ativos e em áreas interiores estendem-se por milhares de quilômetros quadrados, tais como os mega-leques de Kosi e Gandak na planície gangética e os leques do Parapeti, Pilcomaio e Bermejo na planície do Chaco. Os principais fatores controladores do desenvolvimento dos leques são reconhecidamente a alta freqüência de avulsões e a grande quantidade de sedimento de fundo no sistema. Dos mais de $210.000 \mathrm{~km} 2$ do mega-fan do Pilcomaio, cerca de $125.000 \mathrm{~km} 2$ correspondem a uma área ocupada por inúmeras gerações de paleo-canais e áreas pantanosas (Iriondo, 1993). Os mega-leques estão também associados a ativas bacias de subsidência em áreas de plataforma/platô. O leque do rio Taquari no Pantanal, por exemplo, espalha-se por mais de $50.000 \mathrm{~km} 2$ e foi formado por repetidas avulsões, sendo seus lobos distais demarcado por numerosos lagos e freqüentemente inundados (Souza et al., 2002, Assine, 2004, Assine \& Soares 2004, neste volume).

Os mega-leques da planície do Ganges são relativamente bem conhecidos (Wells \& Dorr, 1987, Jain \& Sinhá, 2003a; Sinhá et al. 2002). Rios alimentados por montanhas como o Gondak e Kosi tranferem grande quantidade de sedimentos das áreas fontes montanhosas para a região de piemonte, formando imensos leques. Os depósitos do leque de Kosi mostram um predomínio de fácies arenosas na planície com uma zona bastante estreita de cascalho que se estende cerca de 10 e 20 $\mathrm{km}$ à frente das montanhas. Em trabalho recente, Shukla et al. (2001) reconheceu, no leque do Ganges, quatro zonas diferenciadas de montante a jusante: 1) zona entrelaçada cascalhosa, 2) planície entrelaçada arenosa, 3 ) planície anastomosada e 4) planície meandrante. A arquitetura tri-dimensional dos depósitos de mega-leque consiste de lençóis arenosos de história múltipla (via de regra cascalhosos no trecho superior), intercalados com camadas lamosas de decantação. Estudos da arquitetura dos depósitos aluviais mais superficiais da área interleque do Gandak e Kosi mostram que os 2-3 $\mathrm{m}$ do topo do depósitos consistem predominantemente de seqüências lamosas, com corpos estreitos de areia determinados pelas posições antigas dos canais e algumas camadas arenosas mais raras originadas por rompimentos ("crevasses"). Estudos feitos por meio de afloramentos e sondagens profundas $(300 \mathrm{~m}$ de profundidade) na planície do médio curso do rio 
Baghmati revelaram que os depósitos de planície de inundação distal são formados por uma unidade lamosa com 30 a $50 \mathrm{~m}$ de espessura intercalada com camadas arenosas de 2 a $4 \mathrm{~m}$ de espessura. $\mathrm{Na}$ área interleque de Sharda-Gandak, os últimos 10 a $20 \mathrm{~m}$ de sedimento foram caracterizados por seqüências lamosas, com intercalações de camadas de areia média.

\section{Influência e impacto humanos}

Grandes populações, economia em desenvolvimento, crescimento caótico de áreas urbanas e forte aumento na demanda de água e energia são problemas comuns a todos países tropicais. Contudo, a estratégia de gerenciamento e a magnitude dos recursos fluviais são totalmente diferentes nesses países e isso eventualmente pode afetar o seu desenvolvimento econômico. O Brasil, por exemplo, é um dos maiores produtores agrícolas do mundo devido a um gerenciamento bastante efetivo da água de superfície e subterrânea. Por outro lado, as planícies indo-gangéticas constituem a maior planície aluvial do mundo, mas abrigam uma população de um bilhão de habitantes e apresentam uma agricultura em parte pouco desenvolvida associada à escassez em recursos hídricos. Isso obviamente resulta não apenas na taxa de crescimento do setor agrícola, mas afeta a demanda de água e energia em muitas partes do país.

Outro tópico concerne às grandes cheias da Ásia. As planícies aluviais dos rios Ganges, Brahamaputra e Megna/Barak abrigam mais de 500 milhões de pessoas no Nepal, Índia, Butão e Bangaladesh. Tais rios são cruciais para suprimento de água para irrigação, consumo doméstico e industrial, mas ao mesmo tempo causam imensas perdas de vidas e propriedades devido às cheias. Bangaladesh e Índia, por exemplo, são considerados os países mais inundados do mundo (Baker, 1998). O dano causado pelas cheias aumentou 40 vezes na Índia entre 1950 e 1980, embora parte dessa cifra seja atribuída ao aumento dos assentamentos populacionais no período (Mirza et al., 2001).

A interferência antrópica no sistema fluvial afeta as condições de fluxo natural dos rios de várias maneiras. Construções de barragens nos rios maiores afetam o sistema como um todo, tanto nas taxas de agradação ou degradação de determinados trechos, como na alteração do ecossistema devido às mudanças no suprimento de nutrientes e as profundas alterações, nos pulsos de cheia e vazante (Neiff et al., neste volume). No início da década de 1960 a área total represada do trecho superior da bacia do rio Paraná era de $1000 \mathrm{~km} 2$. Dados recentes indicam que esse valor elevou-se drasticamente para $20.000 \mathrm{~km} 2$ (Agostinho et al., 1994). Grandes reservatório além de estocarem água, retêm uma grande quantidade de sedimento. Estima-se que as barragens do rio Paraná superior estejam retendo 60 na $80 \%$ de sua carga de fundo. Esse valor é ainda mais alto para a bacia do rio Tocantins que tem cerca de $80 \%$ de sua carga de fundo retida por barragem. Represas nos rios Narmada e Krishna na Índia peninsular retêm $75 \%$ dos sedimentos (Vorosmarty et al., 2003).

O rio Orinoco, por sua vez, não é intensamente afetado por barragens, tendo uma única grande represa construída no rio Caroni, um tributário meridional de área cratônica. Esse rio tem uma carga sedimentar bastante reduzida (Warne et al., 2002) e, dessa forma, a descarga sedimentar e de nutrientes que chega ao delta do Orinoco não é praticamente afetada. Situação similar ocorre na bacia do médio e baixo rio Paraná. Todas as barragens de sua bacia encontram-se a montante da confluência com o rio Paraguai. Este rio, por sua vez, contribui com mais de $50 \%$ da carga suspensa do rio Paraná (Orfeo \& Stevaux, 2002). Disso resulta que o delta do rio Paraná não é afetado pela construção das represas.

A dimensão política da bacia de drenagem afeta também os procedimentos de gerenciamento. Muitos dos grandes sistemas fluviais sul-americanos como os rios Tocantins (757.000 km2), Tapajós (490.000 km2), Xingu $(504.000 \mathrm{~km} 2)$, São Francisco $(640.000 \mathrm{~km} 2)$ estão integralmente em território brasileiro. Se por um lado essa situação facilita o planejamento e implantação de programas de gerenciamento do rio, por outro, deixa o país totalmente impune para regular esses imensos sistemas fluviais livre das pressões da comunidade internacional com relação ao impacto ambiental provocado. É o caso das represas planejadas pelo Brasil para os rios Madeira, Araguaia, Xingu e outros, que praticamente não são discutidas pela comunidade internacional. Já a política de gerenciamento de sistemas fluviais que se estende por diferentes países, é geralmente promovida por comissões internacionais. O rio Mecong, por exemplo, é gerenciado pela Comissão do Rio Mecong, órgão internacional formado pela China, Laos Tailândia, Camboja e Vietnã.

Outro exemplo de interferência humana nos rios é a mineração. Na bacia do rio Amazonas, a extração predatória de ouro de aluvião feita por dragas e a exploração dos terraços por garimpeiros predominaram na década de 1980 e início de 1990. Embora o volume de sedimento removido por mineração tenha sido grande, os grandes rios não foram afetados pela introdução de rejeito sedimentar. Contudo, a poluição de água provocada pelo grande influxo de mercúrio foi significativa. Atualmente, a extração de ouro por garimpagem encontra-se mais rara e decadente. Ao contrário, os rios tropicais da Nova Guiné como os da bacia do Fly vêm por décadas sendo degradados pela mineração. O Fly é um rio de tamanho médio e sua carga sedimentar foi significativamente alterada por rejeito de mineração, propiciando um aumento de 85 para 
mais de 100 milhões de toneladas por ano (Milliman et al., 1999). Outras estimativas sugerem uma adição anual de aproximadamente 50 milhões de toneladas de rejeito de mineração, sendo que $3 \%$ são transferidos para a planície de inundação (Dietrich et al., 1999).

\section{Conclusões}

Muitos dos grandes rios e dos mega-leques do mundo estão situados em áreas tropicais. Grandes bacias como as dos rios Amazonas, Orinoco e Congo incluem tributários que estão entre os maiores rios do mundo. Estes sistemas de tributários imensos e complexos necessitam ser analisados individualmente, uma vez que a grande variedade de estilos dos processos sedimentares e geomorfológicos neles atuantes são praticamente desconhecidos. O papel importante dos sistemas tropicais na transferência de sedimentos e nutrientes para os oceanos e áreas costeiras, no estoque de sedimentos nas bacias continentais e no ciclo hidrológico global, mostra que a geomorfologia de rios tropicais não recebeu a atenção necessária quando comparada aos avanços atingidos por outras disciplinas tropicais. Assim, não existe uma dimensão real no potencial de informações úteis que a geomorfologia pode fornecer no tocante ao gerenciamento e planejamento ambiental de bacias fluviais. Os estudos ecológicos em áreas tropicais, por exemplo, também carecem de uma base sólida de conhecimento. A ecologia de ambientes aquáticos tropicais apóia-se em uma base conceitual extremamente pobre ou mesmo ausente no tocante ao funcionamento do hidrossistema físico. Ao mesmo tempo, engenheiros vêm cometendo sérios enganos no manejo da água tropical, não havendo uma boa perspectiva para os programas de transferência inter bacias de água na Índia, assim como as experiências questionáveis na implantação dos caríssimos sistemas de controle de cheias em países pobres como Bangaladesh.

A geologia, e em especial a sedimentologia, poderia atingir avanços significativos para o entendimento de modelos de fácies, reconstrução de paleoambientes e na modelagem de bacias sedimentares se fossem obtidos novos modelos para sistemas tropicias. A geomorfologia de sistemas tropicais, tendo sido provavelmente uma das áreas que mais se desenvolveram nas últimas décadas, poderia desenvolver significativamente seu modelo conceitual de processos fluviais com a obtenção de dados "proxy" de sistemas tropicais. Isso poderia revelar a fraqueza de alguns modelos e conceitos criados para os sistemas fluviais de clima temperado que se transformaram em paradigmas incontestáveis de aplicação universal.

\section{Referências}

Agarwal, R.P. and Bhoj, R., 1992. Evolution of Kosi river fan, India: Structural implication and geomorphic significance. International Journal on Remote Sensing 13(10):1891-1901.

Agostinho, A.A., Borghetti, J.R., Vazzoler, A.E.A.M., and Gomes, A.C., 1994. Itaipu reservoir: Impact on the ichthyofauna and biological bases for its management. In: United Nations Center for Regional Development UNCRD, Nagoya, Japan, Research Report Series, 4:135-148.

Amarasekera, K.; Lee, R.F.; Williams, E.R. and Eltahir, E. 1997. ENSO and natural variability in the flow of tropical rivers. Journal of Hydrology, 200: 24-39.

Assine,M.L., Soares,P.S., 2004. Quartenary of the Pantanal, west-central Brasil. Quartenary International,114:23:34

Arogyaswamy, R.N.P., 1971. Some geological factors influencing the behavior of the Kosi. Records of Geological Survey of India, 96:42-52.

Baker, V.1978. Adjustment of fluvial systems to climate and source terrain in tropical and subtropical environments. In A.D.Miall (ed.) Fluvial Sedimentology, Canadian. Society of Petroleum Geologists, Memoir,5:211-230.

Baker, V. 1998. Future prospects for past floods in India. In: Kale. V. (ed.), Floods Studies in India, Geological Society of India, 219-228.

Balek, J. 1983. Hydrology and water resources in tropical regions. Elsevier, Amsterdam, 271p.

Bristow, C. 1987. Brahmaputra River: channel Migration and Deposition. In: Ethridge, F., Flores, R.M. and Harvey M. (eds.), Recent Development in fluvial Sedimentology. Society of Economic Paleontologists and Mineralogists, Special Publication, 39:6374.

Chandra, S., 1993. Fluvial landforms and sediments in the north-central Gangetic Plain, India. Ph.D (unpublished) Thesis, University of Cambridge, Cambridge, UK.

Coleman, J.M. 1969. Brahmaputra river: channel processes and sedimentation. Sedimentary Geology, 3:129-239.

Dhar, O.N. and Nandargi, S., 2000. A study of rainfall and floods in the Brahmaputra Basin in India. International Journal of Climatology, 20:771-781.

Depetris, P.J. and Kempe, S. 1990. The impact of the El Niño 1982 event on the Paraná River: its discharge and carbon transport. Paleogeography, Palaeoclimatology, Palaeoecology, 89(3):239-244.

Dietrich, W.; Day, G. and Parker, G. 1999. The Fly River, Papua New Guinea: inferences about River Dynamics, floodplain sediementation and fate of sediment. In: Miller, A.J. and Gupta, A. (Eds.), Varieties of Fluvial Form, J. $\mathrm{W}$ il e y \& S o n s, $345-376$.

Drago, E.C. 1990. Hydrological and Geomorphological characteristics of the hydrosystem of the Paraná river. Acta 
Limnológica Brasileira, III:57-62.

Dumont, J.F. and Fournier, M. 1994. Geodynamic environment of Quaternary morphostructures of the Subandean foreland basins of Peru and Bolívia: characteristics and study methods. Quaternary International 21:129-142.

Dumont, J.F. 1993. Lake patterns as related to neotectomics in subsiding basins: the example of the Ucamara Depression, Peru. Tectonophysics, 222: 69-78.

Dunne, T., Mertes, L.A.K., Meade, R.H., Richey, J.E., and Fosberg, B.R.1998. Exchanges of sediments between the flood plain and channel of the Amazon River in Brazil. Geol. Soc. of Am. Bull., 110: 450-467.

Filizola, N.P. 1999. O fluxo de sedimentos em suspensão nos rios da bacia Amazônica Brasileira. ANEEL, Brasília, 63p.

Fortes, E.; Stevaux, J.C. and Volkmer, S. (no prelo). Neotectonics and chanel evolotuin of the lower Ivinhema River: a right bank tributary of the upper Paraná River, Brazil. Geomorphology.

Franzinelli, E. and Igreja, H., 2002. Modern Sedimentation in the lower Negro River, Amazonas State, Brazil. Geomorphology, 44 (3-4):259-272.

Friend, P.F. and Sinha, R., 1993. Braiding and meandering parameters. In: Best, J.L. and Bristow, C.S. (Eds.), Braided Rivers, Geological Society Special: 75:105-111.

Froehlich W. and Starkel L (1993) The effects of deforestation on slope and channel evolution in the tectonically active Darjeeling Himalaya, Earth Surface Processes, 18 (3): 285-290.

Gibss, R. 1967. The Geochemistry of the Amazon River System: Part 1. The factors that control the salinity and the composition and concentration of the suspended solids. Geological Society of American Bulletin, 78, 1203-1232.

Gole, C.V. and Chitale, S.V., 1966. Inland delta building activity of Kosi river. Journal of the Hydraulics Division, Proceedings of the American Society of Civil Engineers, 92 (HY2):111-126.

Goswamy, D. 1998. Fluvial Regime and flood hydrology of the Brahmaputra river, Assam. In: Kale, V. (Ed), Flood studies in India. Geological Society of India, Memoir 41:5375.

Guyoy, J.L., Jouanneau, J.M. and Wasson, J.G. 1999. Characterisation of river bed and suspended sediments in the Rio Madeira drainage basin (Bolivia Amazonia). Journal of South American Earth Sciences, 12:401-410.

Hegde, M., Mathur, V.K. and Mandal, P.S., 1989. Erratic meander shift of the river Ganga at Kanpur. Proceedings of Third International Workshop on Alluvial River Problems (TIWARP). Oxford and IBH Publishing Co. Pvt. Ltd., New Delhi, University of Roorkee, Roorkee, pp. 239-247.
Hidore, J.J and Oliver, J.E. 1993. Climatology: an atmospheric science. Prentice Hall, 436p

Hire, P. S. 2000. Geomorphic and hydrologic studies of floods in the Tapi basin. PhD thesis(Unpublished), University of Pune, India

Iriondo, M. 1993. Late Quaternary and Geomorphology of the Chaco. Geomorphology 7:289-305.

Iriondo, M and Suguio, K. 1981. Neotectonics of the Amazon plain. INQUA Neotectonic, Bulletin, 4:72-78.

Jain V. and Sinha, R. 2003a. River systems in the Gangetic plains and their comparison with the Siwaliks: a review. Current Science, 1025-103.

Jain, V and Sinha, R., 2003b. Hysperavusiveanabraning Baghmati river system, north Bihar plains, eastern India. Z. Geomorph. N.F., 47 (1):101-116.

Kale. V. 1998. Flood studies in India. Geological Society of India, Memoir 41,256p.

Kale, V.S. 1999. Long period fluctuations in monsoon floods in the Decan Peninsula, Índia. Journal of Geological Society of India, 53:5-15.

Latrubesse, E and Franzinelli, E. 2002. The Holocene alluvial plain of the middle Amazon River, Brazil. Geomorphology, 44(3-4):241-257.

Latrubesse , E. and Kalicki, T. 2002. Late Quaternary palaeohydrological changes in the Upper Purus basin, southwestern amazonia, Brazil. Z. Geomorph. N.F., 47(1):129-41.

Latrubesse, E. and Rancy, A.2000. Neotectonic influence on tropical rivers of southwestern Amazon during the late Quaternary: the Moa and Ipixuna river basins, Brazil. Quaternary International, 72:67-72

Latrubesse, E. and Stevaux, J.C. 2002. Geomorphology and Environmental Aspects of Araguaia Fluvial Basin, Brazil. Z. fur.Geomorphol.,129:109-127.

Latrubesse, E. Aquino, S. and Moraes, M. de J. 2002. Floods in the city of Rio Branco, Brazil: a case study on the impacts of human activities on flood dynamic and efects. In: Marchetti, M \& Rivas, V. (eds.), Geomorphology and Environmental Impact Assessment,. Balkema, 163-176.

Leopold, L.B. \& Maddock, T. 1953. The hydraulic geometry of stream channels and some physiographic implications. Professional Paper U.S. Geological Survey. 252:511-537

Martinelli,L.A. Forsberg, B.R., Meade, R.H, and Richey, J.E.1988. Sediment delivery rates for the amazon River and its principal Brazilian Tributaries. Chapman Conference, AGU, Charleston, S.C.Comp. of Ext. Abstract, pp.77-81

Martinelli, L.A., Forsberg, B.R, Victoria , R.L., 
Devol, A.H., Mortatti, J.R., Ferreira,J.,

Bonassi, J. and de Oliveira, E.1993. Suspended Sediment load in the Madeira river. Mitt.Geol.Palaoent.Inst.Univ. Hamburg, 74: 4154.

Meade, R.H., Nordin, Jr., C.F., Hernandez, D.P., Mejía, B.A. and Godoy. J.M. 1983. Sediment and water discharge in rio Orinoco, Venezuela and Colombia. Proceedings of the Second International Symposium on River Sedimentation: water resources and electric power. Nanjing, China, 1134-1144.

Meade, R. 1994. Suspended sediments of the modern Amazon and Orinoco rivers. Quaternary International 21, 29-39.

Meade, R. 1996. River-Sediment inputs to major deltas. In Milliman, J. and Haq, B.U. (Eds.), Sea Level rise and Coastal Subsidence, Kluwer Academic Publishers, 63-85.

Mertes, L.A. 1994. Rates of floodplain sedimentation on the central Amazon River. Geology, 22,171174.

Mertes, L.A., Dunne, T. and Martinelli, L.A. 1996. Channel-floodplain geomorphology along the Solimões-Amazon River, Brazil. Geol. Soc. Am. Bull, 108: 1089-1107.

Miall, A.D. 1996. The Geology of Fluvial Deposits. Springer, $582 \mathrm{p}$.

Milliman, J.D. and Meade, R .1983. World-wide delivery of river sediments to the oceans. J. Geol. 91:1-22.

Milliman, J.D., Farnsworth, K.L. \& Albertin, C. 1999. Flux and fate of fluvial sediments leaving large islands in the East Indies. Journal of Sea Research, 41:97-107.

Mirza, M. Q., Warrick, R.A., Ericksen, N.J. and Kenny, G.J. 2001. Are the floods getting worse in the Ganges, Brahmaputra and Meghna basins?. Environmental Hazards, 37-48.

Mohindra, R., Parkash, B. and Prasad, J., 1992. Historical geomorphology and pedology of the Gandak megafan, Middle Gangetic Plains, India. Earth Surface Processes and Landforms, 17:643662.

Molion, L.C.B. and de Moraes, J.C. 1987. Oscilação do sul e descarga de rios na America do Sul Tropical. Revista Brasileira de Engenharia, Caderno de Recursos Hídricos, 5:53-63.

Mookerjea, D., 1961. The Kosi-A challenge in river control. Journal of the Institution of Engineers (India) 42, pp. 117-142.

Nanson, G. and Knighton, D. 1996. Anabranching rivers: their cause, character and classifications. Earth surface processes and landforms, 21:217239.

Nordin, C.F. and Perez Hernandez, D.1989. Sand waves, bars and wind-blown sands of the Rio Orinoco, Venezuela and Colombia. U.S. Geological Survey, Water Supply Paper, 2326A, $74 \mathrm{pp}$.

Nordin, C.F., Mejia, A. and Delgado, C. 1994. Sediment studies of the Orinoco River, Venezuela. In: Schumm,S. and Winkley,
B.(Eds).The variability of large alluvial rivers. ASCE Press, 243-265.

Orfeo, O. and Stevaux, J.C. 2002. Hydraulic and morphological characteristics of middle and upper reaches of Paraná river (Argentina and Brazil). Geomorphology, N:309-322.

Paoli, C. And Cacic, P. 2000. Régimen de Crecidas y análisis de caudales máximos. In: Paoli, C and Schreider, M. (Eds.), El Rio Paraná en su tramo medio. Tomo I:105-172, UNL, Santa Fé, Argentina.

Paoli, C. and Schreider.M. 2000. El Río Paraná en su tramo medio.Tomo I, UNL, Santa Fé, Argentina, 309p

Phillip, G., Gupta, R.P. and Bhattacharya, A., 1991. LANDSAT image enhancement for mapping fluvial palaeofeatures in parts of Middle Gange Basin, Bihar. Journal of Geological Society of India, 37: 63-74

Phillip, G., Gupta, R.P. and Bhattacharya, A.B., 1989. Channel migration studies in the middle Gange basin, India using remote sensing. International Journal of Remote Sensing 10(6):1141-1149.

Pickup, G. 1984. Geomorphology of tropical rivers, I: Landforms hydrology and sedimentation in the Fly and lower Puraru, Papua New Guinea. In: Schick, A. (Ed.), Catena Supplement, 5:1-18.

Pickup,G, and Warner, R.F. 1984. Geomorphology of tropical rivers, I: Channel adjustment to sediment load and discharge in the Fly and lower Puraru, Papua New Guinea. In. Schick, A. (Ed.) Catena Supplement 5:18-41.

Ramonell, C.G. Amsler, M. and Toniolo, H. 2002. Shifting modes of the Paraná River thalweg in its middle/lower reach. Zeitschrift für Geomorphologie 129:129-142.

Rasanen M .1993. Geologia: la Geohistoria de la Amazonia Peruana. In: Kalliola R, Puhakka M, Danjoy W (eds), Amazonia Peruana, ONERN Universidad de Turku, Turku (Finland), p 4368

Restrepo J.D. and Kjerfve, B. 2000. Magdalena river: interannual variability (1975-1995) and revised water discharge and sediment load estimates. Journal of Hydrology 235: 137149.

Richey, J.E., Nobre,C. \& Deser, C. 1989. Amazon river discharge and climate variability: 19031985. Science, 246: 101-103.

Sabat, J. 1975. Some morphological and hydraulic characteristis of river-patterns in the Zaire basin. Catena, 2: 162-180.

Santos, M.L. and Stevaux, J.C. 2000. Facies and architectural analysis of channel sandy macroforms in the upper Parana river. QuaternaryIinternational, 72: 87-94.

Schumm, S. 1985. Patterns of alluvial rivers. Annual Review of Earth and Planetary Sciences, 13:5-27.

Sinha, R., 1996. Channel avulsion and floodplain structure in the Gandak-Kosi interfan, north 
Bihar plains, India. Zeitschrift fur Geomorphologie, N.F. Suppl.-Bd. 103:249268.

Sinha, R. and Friend, P.F., 1994. River systems and their sediment flux, Indo-Gangetic Plains, northern Bihar, India. Sedimentology, 41:825845.

Sinha, R. and Jain, V., 1998. Flood hazards of north Bihar rivers, Indo-Gangetic Plains. Memoir Geological Society of India ,41:27-52.

Sinha, R, Khanna, M. Jain, V. and Tandon, S.K, 2002. Mega-geomorphology and sedimentation history of parts of the GangaYamina plains. Current Science, 84(5):562566.

Smith, D.G. 1986. Anastomosing river deposits sedimentation rates and basin subsidence, Magdalena River, Northwestern Colombia, South America. Sedimentary Geology, 46:177196.

Shukla, U.K., Singh, I.B., Sharma, M. and Sharma, S., 2001. A model of alluvial megafan sedimentation : Ganga megafan. Sedimentary Geology, 144:243-262.

Souza, O.C.A. de, , M., Mertes, L.A.K. and Melack, J.M. 2002. Forms and process along the Taquarí River Alluvial Fan, Pantanal, Brazil. Zeitschrift für Geomorphologie, 129, 73-107.

Stevaux, J.C. 1994. The upper Paraná river (Brazil): geomorphology, sedimentology and paleoclimatology. Quaternary International, 21:143-161.

Stevaux, J.C. 2000. Climatic Events during the Pleistocene and Holocene in the upper Paraná River: correlation with NE Argentina and South-Central Brazil. Quaternary International, 77: 87-94.

Stevaux, J.C. \& Santos, M.L., 1998. Palaeohydrological changes in the upper Paraná River, Brazil, during the Late Quaternary: a facies approach. In: Benito, G.; Baker, V.R. and Gregory, K.J. (Eds). Paleaohydrology and Environmental Change. John Wiley \& Sons Ltd., p. 273-285.

Tangri, A.K., 1986. Understanding the dynamics of Ghaghra river system in Uttar Pradesh, India, using satellite remote sensing, Proceedings of the seventh Asian conference on remote sensing. Korean Society of Remote Sensing, Asian Association on Remote Sensing, Seoul, Korea: 1 - 6 .

Thorne, C.R., Russell, A.P. G., and Alam M. K. (1993) Planform pattern and channel evolution of the Brahmaputra river, Bangladesh. In: Best, J.L. \& Bristow, C.S. (Eds.) Braided Rivers, Geol. Soc. London, 257-276.

Tricart, J. 1977. Types de lits fluviaux en Amazonie Bresilienne. Ann. Geog., 437:1-54.

Tricart, J., Pagney, P. and Frecaut, R. 1984. Le Pantanal (Brèsil) Etude Ecogeographique. Geomorphologie. Travaux et Documents de Geographie Tropicale CEGET, 52:7-92.
Vital, H and Stattegger, K. 2000. Lowermost Amazon River: Evidences of Late Quaternary sea level fluctuations in a complex hydrodynamic system. Quaternary International, 72:53-60.

Vorosmarty,Ch., Meybeck, M., Fekete, B., Sharma, K., Green, P and Syvytski, J. 2003. Antrhopogenic sediments retention: major global impact from registered river impoundments. Global and Planetary Changes, 39:169-190.

Warne, A., Meade,R., White, W.A., Guevara, E.H. Gibeaut, J., Smyth, Aslan, A. And Tremblay,T. 2002. Regional controls on geomorphology, hydrology, and ecosystem integrity in the Orinoco delta, Venezuela. Geomorphology, 44(3-4):273-307.

Wells, N and Dorr, J.A. 1987. A reconnaissance of sedimentation on the Kosi alluvial fan of India. In: Ethridge, F., Flores, R.M. and Harvey M. (Eds.), Recent Development in fluvial Sedimentology. Society of Economic Paleontologists and Mineralogists, Special Publication, 39:51-61.

Winkley, B.R., Ordonez, J.I., Saenz, J.E. and Duque, R. 1994.The Magdalena river, Colombia. In; Schumm, S and winkler, B. (eds.), The variability of Large Alluvial rivers. ASCE Press, 139-160. 